\title{
Investigação e reprodução assistida no tratamento da infertilidade masculina
}

\author{
Investigation and assisted reproduction in the treatment \\ of male infertility
}

Palavras-chaves

Infertilidade masculina/terapia Fertilização in vitro Injeções de esperma intracitoplásmicas Técnicas reprodutivas assistidas Varicocele/cirurgia

Keywords

Infertility, male/therapy Fertilization in vitro Sperm injections, intracyłoplasmic Reproductive techniques, assisted Varicocele/surgery
Correspondência:

Fabio Firmbach Pasqualotto Rua Pinheiro Machado, 2569, sl 23/24 CEP 95020-172 - São Pelegrino - Caxias do Su//RS Fone: (54) 3214-4095 - Fax: (54) 3215-1695 E-mail:fabio@conception-rs.com.br

Recebido 05/01/2007

Aceito com modificacões $18 / 01 / 2007$

\section{Resumo}

A infertilidade masculina afeta 10\% dos casais em idade reprodutiva em todo o mundo e pode ser tratada em muitos casos. Além de outras etiologias bem documentadas como causadoras da infertilidade masculina, as causas genéticas cada vez mais têm sido diagnosticadas. Reconstrução microcirúrgica do trato reprodutivo ou varicocelectomia é preferível à captação de espermatozóides com fertilização in vitro e injeção intracitoplasmática de espermatozóides em homens vasectomizados ou com varicocele na ausência de fatores de risco para infertilidade feminina. Se ocorrer uma obstrução epididimária após a vasectomia ou se a mulher possuir uma idade avançada, a decisão para reconstrução microcirúrgica ou captação de espermatozóides com fertilização in vitro ou injeção intracitoplasmática de espermatozóides deve ser individualizada. Captação espermática com fertilização in vitro e injeção intracitoplasmática de espermatozóides é preferível ao tratamento cirúrgico quando o tratamento do fator feminino requer fertilização in vitro ou quando as chances de sucesso com a captação de espermatozóides e injeção intracitoplasmática de espermatozóides são superiores às chances com o tratamento cirúrgico.

\section{Abstract}

Male infertility affects $10 \%$ of couples in the reproductive age worldwide and is treatable in many cases. In addition to other well-described etiologies, genetic causes of male infertility are now more commonly diagnosed. In men with prior vasectomy or varicocele, microsurgical reconstruction of the reproductive tract or varicocelectomy is more costeffective than sperm retrieval with in vitro fertilization and intracytoplasmic sperm injection if no female fertility risk factors are present. If epididymal obstruction after vasectomy is detected or advanced female age is present, the decision to use either microsurgical reconstruction or sperm retrieval with in vitro fertilization and intracytoplasmic sperm injection should be individualized. Sperm retrieval with in vitro fertilization and intracytoplasmic sperm injection is preferred to surgical treatment when female factors requiring in vitro fertilization are present or when the chance for success with sperm retrieval and intracytoplasmic sperm injection exceeds the chance for success with surgical treatment.
Centro de Ciências Biológicas e da Saúde da Universidade de Caxias do Sul - UCS - Caxias do Sul (RS) e Conception - Centro de Reprodução Humana, Caxias do Sul (RS), Brasil.

Diretor do Centro de Reprodução Humana, Caxias do Sul (RS); Professor Doutor Titular da Unidade Morfológica da Faculdade de Medicina da Universidade de Caxias do Sul - UCS - Caxias do Sul (RS), Brasil. 


\section{Introdução}

Infertilidade pode ser definida como a inabilidade de um casal sexualmente ativo, sem a utilização de métodos contraceptivos, de estabelecer gravidez dentro de um ano, período no qual por volta de $90 \%$ dos casais o fazem ${ }^{1}$. Ela é um fenômeno universal que atinge aproximadamente 8 a $15 \%$ dos casais, independente dos fatores socioeconômicos ou culturais ${ }^{1,2}$. Apesar de o fator masculino representar até $50 \%$ das causas de infertilidade, a importância da avaliação e do tratamento do homem infértil tem sido atualmente questionada ${ }^{2}$. Contudo, existem relatos de casos e até séries de pacientes publicados na literatura com doenças potencialmente graves e até mesmo letais, como câncer de testículo, que podem ser encontradas em homens inférteis.

A primeira indicação de uma piora na qualidade do ejaculado surgiu quando da realização de uma metaanálise de 14.947 homens normais provenientes de 61 centros diferentes ${ }^{3}$. Este estudo indicou que houve uma diminuição de aproximadamente $50 \%$ na concentração espermática no período de 1938 a 1990. Deve ser realizada uma análise mais crítica desses resultados, pois existe uma falta de padronização na metodologia usada para monitorar a concentração espermática e as influências da idade, raça, localização geográfica e freqüência da ejaculação. No entanto, apesar de possíveis erros na metodologia empregada, a existência de uma correlação negativa entre a concentração espermática e o ano é um fenômeno difícil de ser negado. Evidências adicionais sobre a mudança na função das células germinativas estão indicadas pelo alarmante crescimento na incidência de câncer de testículo (tumores de células germinativas), o qual está aumentando na proporção de 2 a $4 \%$ ao ano em homens com idade inferior a 50 anos $^{4}$. Apesar de estes dados sugerirem uma deterioração na função testicular humana, os mecanismos patológicos envolvidos não estão estabelecidos ${ }^{5}$. A hipótese de as espécies reativas de oxigênio serem uma causa importante nas alterações na função testicular é uma proposta que tem ganhado credibilidade com grande variação de implicações para a saúde e fertilidade da espécie humana ${ }^{6}$.

\section{Anamnese}

Uma vez que o casal deve ser considerado como uma unidade (casal infértil) e avaliado em paralelo, é importante que o médico responsável pelo homem esteja a par da avaliação de sua parceira ${ }^{7,8}$. Uma cuidadosa e meticulosa avaliação da história clínica do paciente com infertilidade é de importância relevante na constatação da etiologia da infertilidade masculina, porque, por meio dela, podemos ter um diagnóstico presuntivo das causas em até um quarto dos $\operatorname{casos}^{7,8}$. Devemos realizá-la na presença da esposa e ser simples e objetiva, avaliando desde antecedentes familiares até a história conjugal ${ }^{7,8}$.

\section{Exame físico}

O exame físico do homem infértil deve ser cuidadoso, uma vez que qualquer fator que potencialmente afete a saúde pode repercutir sobre a espermatogênese ou revelar a presença de doenças sistêmicas graves ${ }^{7,8}$. O exame físico deve ser realizado com o intuito de detectar anormalidades não só referentes ao aparelho genital, mas também de outros sistemas que possam interferir na capacidade de espermatogênese do paciente ${ }^{7,8}$.

\section{Análise seminal}

Após a coleta da história e realização do exame físico, a análise seminal deve ser a primeira fonte de informação para o médico?. A análise seminal deve ser realizada com cuidado, pois pode fornecer dados sobre a espermatogênese e a permeabilidade do trato reprodutivo. Tradicionalmente, o diagnóstico de infertilidade masculina depende de uma avaliação descritiva dos parâmetros do ejaculado, com ênfase na concentração, motilidade e morfologia dos espermatozóides ${ }^{9}$. Acreditava-se que a análise seminal era o teste considerado padrão ouro para avaliar a capacidade fértil do homem; entretanto, pesquisas mostram que mais de $80 \%$ dos homens inférteis possuem concentrações espermáticas que excedem os valores de normalidade da Organização Mundial da Saúde (OMS). Desta forma, é necessário enfatizar que a análise seminal não é um teste de fertilidade ${ }^{9}$. A avaliação de fertilidade é um fenômeno complexo e multifatorial que envolve a avaliação do casal $^{2,9}$.

Além disso, estudos recentes sugerem que a espermatogênese seja inferior a 60 dias, ao contrário dos 70 a 80 dias propagados por 40 anos; então, uma análise seminal individual reflete as variações biológicas que ocorreram nos últimos dois meses ${ }^{10}$. O período de abstinência para realização da análise seminal deve ser entre dois a três dias. Para uma avaliação mais fidedigna e real da espermatogênese, são recomendáveis no mínimo duas coletas de sêmen com intervalo de tempo entre as coletas de aproximadamente 15 dias. Se os resultados provenientes do espermograma diferirem muito entre si, uma nova 
análise seminal deverá ser realizada. Para otimizar os resultados, recomenda-se que a primeira análise seja básica, e de acordo com os resultados iniciais, na segunda coleta devem-se solicitar exames complementares e testes de função espermática e processamento seminal prognóstico.

Por razões de padronização e para que os resultados obtidos em locais diferentes sejam comparáveis e confiáveis, os testes que envolvem sêmen devem ser realizados de acordo com diretrizes, como, por exemplo, as estabelecidas pela OMS ${ }^{1}$. De acordo com a OMS, o sêmen é considerado normal quando: a concentração de espermatozóides é superior a $20 \times 10^{6} \mathrm{~mL}$; o número total de espermatozóides é superior a 40 milhões; e a motilidade dos espermatozóides é superior a 50\% das células com progressão linear ${ }^{1}$. Entretanto, evidências sugerem que sêmen com concentração superior a $48 \times 10^{6} \mathrm{~mL}$ e motilidade de $63 \%$ pode ser considerado normal ${ }^{11}$. Considera-se normal um sêmen com pelo menos $50 \%$ de formas móveis (graus $\mathrm{A}+\mathrm{B}$ ). A morfologia pelo critério da OMS é considerada normal quando pelo menos $30 \%$ dos espermatozóides apresentam formas ovais normais. A avaliação da morfologia requer mais habilidade e experiência do que a avaliação da densidade e da motilidade dos espermatozóides. A introdução do critério estrito de Tygerberg (também conhecido como Kruger) ${ }^{12}$ e o estabelecimento de um ponto de corte de $14 \%$ para morfologia normal correlaciona-se com sucesso em ciclos de fertilização in vitro (FIV).

Testes complementares à análise seminal de importância diagnóstica

Experiências clínicas revelaram que não é exatamente o número absoluto de espermatozóides que prediz o prognóstico de fertilidade, mas a sua capacidade funcional $^{9}$. O desenvolvimento de um teste com grande poder para predizer a fertilização pelos espermatozóides é o objetivo primordial de qualquer laboratório de pesquisa em andrologia.

Apenas as provas de função espermática - como reação acrossômica, receptores de manose na superfície dos espermatozóides, interação espermatozóide-muco cervical, testes da penetração espermática e hemizona, níveis de creatina quinase, espécies reativas de oxigênio, capacidade antioxidante total e peroxidação lipídica - podem dar informações referentes à probabilidade de esse homem vir a engravidar a sua parceira ${ }^{13}$. Estes testes podem auxiliar na indicação de cirurgias para infertilidade masculina, até ajudar a escolher a técnica mais apropriada para reprodução assistida, com uma boa relação custo-benefício.

\section{Avaliação hormonal}

As recomendações atuais para avaliação endócrina no homem infértil são: concentração espermática $<10 \times 10^{6}$ espermatozóides $/ \mathrm{mL}$, disfunção erétil, outros sinais e sintomas de baixos níveis de testosterona ou endocrinopatia relacionada. A avaliação inicial deverá incluir níveis séricos de testosterona e hormônio folículo estimulante. Caso a testosterona esteja baixa, avaliar testosterona total, livre e globulina de ligação hormonal sérica, hormônio luteinizante e prolactina pela manhã. Muito embora endocrinopatias sejam encontradas em $10 \%$ dos homens testados, endocrinopatias clinicamente significativas são encontradas em $<2 \%$ dos homens ${ }^{7,8}$.

\section{Avaliação genética}

Existe atualmente um aumento no diagnóstico de anormalidades genéticas que estão sendo identificadas como causadoras da infertilidade masculina ${ }^{7,8,14}$. A incidência de oligozoospermia grave (abaixo de 5 milhões de espermatozóides $/ \mathrm{ml}$ ) e azoospermia é de aproximadamente 10 a $12 \%$ de toda a população masculina infértil ${ }^{14}$. Embora a injeção intracitoplasmática de espermatozóides (ICSI) represente um dos principais avanços na abordagem do homem infértil, existem considerações importantes relativas ao potencial de transmissão de anormalidades genéticas para a prole, uma vez que os processos de seleção natural dos espermatozóides são ultrapassados ${ }^{15}$.

Os três fatores genéticos mais freqüentemente relacionados à infertilidade masculina são: aberrações cromossômicas, mutações gênicas e microdeleções do cromossomo Y. Na população de homens inférteis, a incidência de alterações cromossômicas varia de 6 a $7 \%$, aumentando à medida que diminui a concentração espermática (cerca de $16 \%$ nos homens azoospérmicos). A síndrome de Klinefelter (47,XXY) é a mais freqüente das aberrações cromossômicas entre os homens inférteis, atingindo 7 a $13 \%$ dos azoospérmicos, podendo haver indivíduos com esta síndrome e cariótipo em mosaico (46,XY/47,XXY e outros), com graus variáveis de comprometimento da espermatogênese. São também importantes as alterações estruturais envolvendo autossomos e/ou cromossomos sexuais. A freqüência de translocações equilibradas nos homens inférteis é cerca de 5 a $10 \%$, perfazendo uma chance dez vezes superior à observada nos homens normais ${ }^{7,8,15}$.

A fibrose cística, que é uma doença autossômica recessiva que acomete um em 2500 indivíduos cau- 
casianos, é potencialmente fatal para a prole ${ }^{15}$. Em homens com azoospermia obstrutiva devido à agenesia congênita dos vasos deferentes a pesquisa do Cystic Fibrosis Transmembrane Conductance Regulator gene (CFTR) deve ser realizada. Caso o paciente apresente alguma mutação, deve-se proceder à pesquisa na parceira.

O gene SRY presente no braço curto do cromossomo $\mathrm{Y}(\mathrm{Yp})$ é fundamental para a diferenciação e crescimento testicular. A pesquisa da microdeleção do cromossomo Y é importante para definir a etiologia da falência da espermatogênese, assim como conceder informações preciosas a respeito do manejo clínico mais apropriado do paciente infértil e do menino nascido da ICSI ${ }^{15}$.

Quando comparadas com outras causas conhecidas de infertilidade, as microdeleções do cromossomo $\mathrm{Y}$ são relativamente freqüentes (7 a 10\%) e sua freqüência aumenta com o grau de comprometimento da espermatogênese (16\% em azoospérmicos). Desta forma, a microdeleção do cromossomo Y é uma causa comum de falência na espermatogênese. Três regiões do braço longo do cromossomo Y, denominadas AZFa, $\mathrm{AZFb}, \mathrm{AZFc}$, têm sido propostas como associadas à aplasia de células germinativas, parada da maturação e hipoespermatogênese, respectivamente. Desta forma, em mais de $50 \%$ dos pacientes azoospérmicos com deleção na região AZFc, espermatozóides maduros podem ser encontrados. Deve-se pesquisar microdeleções de cromossomo $\mathrm{Y}$ em todo homem com concentração espermática inferior a 5 milhões de espermatozóides $/ \mathrm{mL}$.

\section{Ultra-sonografia testicular}

É útil na determinação do volume testicular, o qual pode ser difícil de avaliar em pacientes com cirurgia escrotal prévia e grandes hidroceles ${ }^{7,8}$. Além disso, ela contribui para a identificação de tumores testiculares de pequeno tamanho, encontrados em cerca de 0,5 a $1,2 \%$ dos pacientes que consultam para infertilidade, em comparação com a incidência de $0,005 \%$ na população masculina geral.

A dilatação das veias do plexo venoso pampiniforme (varicocele) também pode ser comprovada pela ultrasonografia testicular. A ultra-sonografia com dopler de alta resolução é uma ferramenta adicional que pode mostrar concomitantemente o fluxo sangüíneo, podendo ser solicitada em casos selecionados. Por outro lado, é importante destacar que, como consenso, apenas varicoceles clinicamente detectáveis apresentam melhora na qualidade seminal se o paciente for submetido a um procedimento cirúrgico ${ }^{16}$.

\section{Análise da estrutura da cromatina espermática}

Evidências recentes sugerem que a integridade da cromatina do DNA seja muito importante para a fertilidade masculina ${ }^{17}$. A estrutura da cromatina do espermatozóide (proteínas associadas ao DNA) pode ser mensurada por vários métodos, incluindo os ensaios Tunnel e Cometa, assim como citometria de fluxo após tratamento com ácido e coloração dos espermatozóides com laranja de acridina ${ }^{7}$. Estes testes avaliam o grau de fragmentação de DNA que ocorre após tratamento químico do complexo DNA-cromatina dos espermatozóides e que podem refletir indiretamente a integridade da qualidade do DNA dos espermatozóides. DNA fragmentado em excesso raramente ocorre em homens férteis, mas pode ser encontrado em $5 \%$ dos homens inférteis com qualidade seminal normal e $25 \%$ dos homens inférteis com análise seminal alterada. Este teste pode detectar infertilidade que porventura não tenha sido diagnosticada em uma análise seminal. Muitas vezes reversível, as causas de fragmentação do DNA incluem o uso de cigarros, algumas patologias, hipertermia, poluição atmosférica, infecção e varicocele. A indicação atual para a pesquisa do DNA dos espermatozóides é a presença de infertilidade sem causa aparente.

Atualmente acredita-se que os espermatozóides provenientes do testículo em homens azoospérmicos apresentem menor fragmentação do DNA comparado aos do epidídimo quando da presença de azoospermia obstrutiva. Isto talvez decorra do fato de que a fragmentação do DNA do espermatozóide ocorre no momento da sua liberação das células de Sertoli. Porém, estudos demonstram que o espermatozóide do epidídimo resulta em maiores taxas de gravidez comparado ao espermatozóide do testículo ${ }^{18}$.

Acredita-se também que pacientes com oligozoospermia grave (concentração inferior a $1 \times 10^{6}$ espermatozóides $/ \mathrm{mL}$ ) talvez devam ser submetidos a técnicas de extração ou punção de espermatozóides do testículo e ICSI e não usar os espermatozóides do ejaculado, pela presença de DNA fragmentado nos espermatozóides do ejaculado em maior freqüência do que no testículo ${ }^{17}$. Porém, mais estudos devem ser feitos para comprovar tal fato.

\section{Exame de urina pós-ejaculação}

Para diagnosticar ejaculação retrógrada a urina pós-ejaculação deve ser avaliada quanto à presença de espermatozóides. Este exame pode diferenciar a ejacu- 
lação retrógrada de outras causas de baixo volume de ejaculado $(<1,5 \mathrm{~mL})$ incluindo erro de coleta, hipoandrogenismo, obstrução de ducto ejaculador e ausência congênita bilateral dos vasos deferentes ${ }^{7,8}$.

\section{Tratamento da infertilidade masculina (ênfase em reprodução assistida)}

Em primeiro lugar, é importante assegurar que o potencial reprodutivo feminino esteja adequado para tolerar no mínimo 6 a 12 meses, tempo este considerado adequado para o tratamento da maioria das causas masculinas passíveis de correção ${ }^{2}$. A decisão em selecionar tratamentos clássicos da infertilidade masculina inclui o tratamento da varicocele e a reversão de vasectomia ${ }^{19}$. Classicamente, a literatura urológica coloca estes dois tratamentos cirúrgicos de excelente relação custo-benefício com relação às técnicas de reprodução assistida ${ }^{20}$. Estas recomendações são baseadas em modelos de análises de decisões custo-benefício. A infertilidade masculina pode ser corrigida ou não, e pode ser tratada especificamente ou não.

Dentre as condições masculinas passíveis de correção incluem-se o período de abstinência sexual e a época do ciclo menstrual na qual o casal mantém relação sexual, anormalidades na ejaculação causadas por hipospádias graves, disfunção erétil, fimoses muito graves, ejaculação retrograda, álcool, maconha, heroína, pesticidas como dibromocloropropano, medicamentos como cetoconazol, espironolactona e cimetidina ${ }^{21}$.

Outra grande causa de infertilidade masculina é a infecção do trato genital. No entanto, embora a infecção do trato genital possa estar ligada com infertilidade em estudos epidemiológicos, uma correlação entre micro organismos em particular e a infertilidade não foi estabelecida ${ }^{7,8}$. Por outro lado, vários produtos provenientes de leucócitos ativados podem estar presentes no sêmen e prejudicar a qualidade seminal. Além disso, existe uma série de produtos provenientes dos leucócitos, como as espécies reativas de oxigênio, que podem causar peroxidação lipídica da membrana dos espermatozóides e por fim levar ao dano de DNA ${ }^{22}$. Devido ao fato de $83 \%$ de todos os homens inférteis terem culturas positivas no sêmen e de que uma relação positiva entre culturas bacterianas e infertilidade ainda ser inconclusiva, as culturas seminais devem ser obtidas apenas quando: existe uma história prévia de infecção genital, secreção prostática alterada, presença de $>1000$ bactérias patogênicas $/ \mathrm{mL}$ no sêmen e presença de $>1$ milhão de leucócitos no sêmen (piospermia) ${ }^{7,8}$.

Estudos não controlados sugerem que as taxas de gravidez podem melhorar com o uso de antibióticos; porém, tratamento adicional com antioxidantes talvez deva ser usado associado com antibióticos.

\section{Varicocele e reprodução assistida}

A introdução da técnica de ICSI no oócito possibilitou que muitos homens com alterações seminais gerassem seus próprios filhos ${ }^{19}$. Com ela, homens com infertilidade masculina grave podem ter descendentes gerados com seu material genético. A correção cirúrgica da varicocele permanece uma excelente opção para devolver fertilidade ao casal com uma relação custo-benefício muito superior a qualquer procedimento de reprodução assistida. Espera-se uma melhora nos parâmetros seminais após correção da varicocele de aproximadamente 70 a $120 \%$, e uma taxa de gravidez de aproximadamente $33-46 \%$ num período de até 12 meses após a cirurgia, sendo que a melhora nos parâmetros espermáticos ocorre num período de seis a nove meses após a cirurgia ${ }^{23,24}$. É importante destacar que a idade da parceira é de fundamental importância na orientação do melhor tratamento do paciente com varicocele, ou seja, homens cujas parceiras apresentam idade superior a 37 anos não devem ser submetidos à varicocelectomia, e sim o casal deve ser encaminhado para clínicas de reprodução assistida. Entretanto, o paciente jovem deve ser submetido à varicocelectomia, visto que estudo recente demonstrou que, em pacientes submetidos a um procedimento de inseminação intrauterina, a porcentagem de pacientes que estabeleceu gravidez foi superior nos pacientes operados de varicocele $(33,3 \%)$ comparado a pacientes portadores de varicocele e que não foram submetidos ao procedimento cirúrgico de correção da varicocele $(11 \%)^{25}$. Desta forma, a varicocelectomia é superior (relação custo-benefício) a qualquer técnica de reprodução assistida.

Com o advento das técnicas de reprodução assistida, muitos profissionais que tratam o casal infértil têm oferecido como tratamento de escolha a ICSI. Entretanto, estudos demonstram que a FIV/ICSI, além de não ser mais eficaz que a varicocelectomia, do ponto de vista econômico, ela é muito mais cara que o reparo cirúrgico da varicocele. Schlegel ${ }^{26}$ demonstrou que o custo por nascimento com FIV/ICSI foi de US\$89.091 comparado a US\$26.268 após a varicocelectomia. Assim sendo, a varicocelectomia é mais vantajosa do que as técnicas de reprodução assistida.

Desta forma, pacientes com varicocele clinicamente detectável e com esposas de idade inferior a 38 anos devem ser submetidos à varicocelectomia. Entretanto, quando a esposa tiver mais de 37 anos de idade, técnicas de reprodução assistida devem ser consideradas 
de primeira escolha ${ }^{25}$. É importante destacar que a análise seminal deve ser realizada a cada três meses após a varicocelectomia por pelo menos um ano ou até o paciente estabelecer a gravidez de sua parceira. A inseminação intra-uterina ou as técnicas de reprodução assistida devem ser estimuladas quando a infertilidade conjugal permanecer apesar de uma varicocelectomia anatomicamente bem realizada.

O tratamento cirúrgico elimina com sucesso mais de $90 \%$ das varicoceles. A Associação Americana de Urologia e a Sociedade Americana de Medicina Reprodutiva recentemente descreveram que o reparo da varicocele deve ser considerado como a primeira opção de tratamento quando da presença de infertilidade associada com varicocele e exames normais das parceiras ${ }^{27}$. Eles observaram que a maioria dos especialistas realiza a abordagem microcirúrgica inguinal ou subinguinal para aumentar as chances de preservação dos vasos arteriais e linfáticos e reduzir a chance de persistência ou recorrência da varicocele. Apesar de estes comentários partirem de um grupo de 12 especialistas e 125 consultores da área da infertilidade masculina, qualquer profissional envolvido com medicina reprodutiva, planejamento familiar ou urologista sabe sobre a eterna discussão a respeito da fisiopatologia ou tratamento da varicocele. Além disso, Evers e Collins ${ }^{28}$, ao realizar uma revisão sistemática de sete estudos controlados, observaram que a varicocelectomia não foi efetiva para o tratamento da infertilidade nos pacientes com varicocele clinicamente detectáveis. Entretanto, esta meta-análise talvez não tenha poder suficiente para detectar pequenas alterações pelo baixo número de pacientes em alguns grupos de pacientes operados. Infelizmente, tirar esta conclusão deste estudo é no mínimo equivocado, visto que os dados nesta meta-análise são questionáveis. Especificamente, muitos pacientes neste estudo apresentaram uma análise seminal considerada normal. Dos sete estudos incluídos na meta-análise, quatro envolveram pacientes com varicocele subclínica. Nenhum dos pacientes foi avaliado com relação a anormalidades genéticas ou moleculares. Dois destes estudos apresentam resultados questionáveis com relação ao grupo controle, incluindo um com taxas de gravidez no grupo controle de $47 \%$ e o outro com $24,5 \%$ associado a aconselhamento e tratamento para melhorar a função reprodutiva feminina. As taxas de gravidez nos demais grupos controle variaram de 4,5 a $10 \%$. Finalmente, o tratamento da varicocele não incluiu procedimentos microcirúrgicos assim como limitado acompanhamento dos pacientes para avaliar recorrências com a cirurgia ou embolização.

De uma maneira geral, a cirurgia de correção da varicocele (subinguinal microcirúrgica) em pacientes com varicocele clinicamente detectável, independe da histologia testicular, tipo de alteração na qualidade seminal ou níveis de FSH antes da cirurgia. Pacientes azoospérmicos talvez devam ser submetidos à varicocelectomia antes de serem encaminhados para clínicas de reprodução assistida. Quanto maior o grau de varicocele, maior é a chance de melhora na qualidade seminal após a varicocelectomia. Entretanto, pacientes com esposas com idade superior a 37 anos devem ser submetidos a técnicas de reprodução assistida e não à varicocelectomia ${ }^{24}$.

\section{Reversão de vasectomia}

Embora azoospermia obstrutiva seja causa de infertilidade masculina em baixa percentagem comparada a outras causas como varicocele, é o seu diagnóstico que atrai atenção do ponto de vista custoefetividade. Esta atenção maior é atribuída ao fato que a vasectomia é a forma mais comum de obstrução encontrada no tratamento da infertilidade. Reversão de vasectomia é requisitada por 2 a $6 \%$ dos homens para restaurar a fertilidade. Além disso, a reversão de vasectomia é considerada uma modalidade efetiva de tratamento que tem sido muito utilizada pela comunidade urológica ${ }^{29}$.

Até recentemente, o único tratamento disponível para restaurar a fertilidade após vasectomia era a reconstrução do trato reprodutivo. O tratamento dos pacientes com obstrução do trato seminal varia desde o reparo microcirúrgico da obstrução ou captação espermática e FIV com ICSI. Correção cirúrgica é realizada por meio da microcirurgia dos vasos deferentes ou epidídimo mas, antes de realizar o procedimento cirúrgico, a parceira deve ser avaliada para determinar se existe infertilidade feminina. Além disso, o procedimento microcirúrgico tem uma melhor relação custo-efetividade do que captação de espermatozóides e FIV ou ICSI, os quais requerem intervenção em ambos os componentes do casal. De máxima importância, a reconstrução microcirúrgica, caso tenha sido um sucesso, permite que os casais tenham mais filhos sem assistência médica adicional.

Desta forma, na maioria dos casos, a reconstrução microcirúrgica é mais apropriada como tratamento inicial da azoospermia obstrutiva. Embora existam muitas dificuldades técnicas que possam resultar em falhas técnicas imediatas ou tardias, os resultados de vasovasostomia resultam em restauração dos espermatozóides no ejaculado (permeabilidade) em aproximadamente $90 \%$ dos pacientes. Taxas de gravidez de 44 a $60 \%$ e de nascimentos vivos variam de 36 a $47 \%^{20}$. 
A vasoepididimostomia (VE) é considerada um dos procedimentos microcirúrgicos mais difíceis de serem realizados por urologistas. As taxas de sucesso têm melhorado de maneira significativa com o desenvolvimento de anastomoses microcirúrgicas término-terminais ou término-laterais utilizando túbulos específicos. As taxas de sucesso relatadas para a VE são consideravelmente inferiores àquelas descritas com a vasovasostomia. As taxas de permeabilidade para a VE variam de 70 a $85 \%$ e as taxas de gravidez variam de 31 a $56 \%$ no tratamento do homem com obstrução epididimária independente da causa. Os melhores resultados são alcançados com cirurgiões com treinamento e experiência em microcirurgia ${ }^{19,20}$.

Entretanto, existem situações nas quais a captação espermática com FIV/ICSI pode ser considerada de eleição para casais em que o homem apresenta azoospermia obstrutiva; apesar disto, o sucesso e a ampla disposição da FIV/ICSI tem resultado em controvérsia sobre o manejo mais efetivo desta condição. A técnica de ICSI deve ser realizada em quase todos os casos em que o espermatozóide é retirado do testículo ou epidídimo de um homem com azoospermia obstrutiva, porque as técnicas de captação espermática raramente produzem uma quantidade suficiente de espermatozóides para realizar inseminação intrauterina ou FIV sem micromanipulação de gametas. A técnica de ICSI fornece taxas de fertilização de 45 a $75 \%$ por oocito inseminado quando o espermatozóide é retirado cirurgicamente do epidídimo ou testículo ${ }^{18}$. De uma maneira geral, as taxas de gravidez clínica variam de 26 a 57\% e as de recém-nascidos vivo em boas condições variam de 18 a $54 \%$.

A idade da parceira é importante porque a fertilidade feminina diminui progressivamente após os 35 anos de idade e é limitada após os 40 anos. Devido ao fato de que o intervalo médio entre a reversão de vasectomia e a gravidez pós-procedimento seja de 12 meses, casais devem considerar a captação espermática com ICSI quando a parceira possui mais de 37 anos de idade. Muito embora em casais nos quais a parceira possui 40 anos de idade as taxas de sucesso com FIV com ou sem ICSI diminuam rapidamente, foi demonstrado recentemente que vale a pena realizar reconstrução microcirúrgica do trato masculino, mesmo em casos em que a parceira tenha idade superior a 35 anos de idade. Mulheres com mais de 35 anos de idade devem ser sempre avaliadas antes de qualquer tratamento adotado para infertilidade $\mathrm{e}^{7,8}$.

Claramente, o custo por nascimento para reconstrução em casos de azoospermia obstrutiva é menor do que os associados com FIV/ICSI. Esta informação deve ser usada na decisão do algoritmo para os casais que desejam ter o retorno do potencial fértil após a vasectomia. A decisão final sobre o melhor método, reconstrução microcirúrgica ou captação de espermatozóide com FIV/ICSI, é idealmente feita pelo casal bem informado em conjunto com o especialista em medicina reprodutiva ${ }^{19,20}$.

\section{Reprodução assistida e fator masculino}

Inseminação intrauterina é um método muito utilizado para o tratamento de diversos tipos de infertilidade. Nos dias de hoje, a inseminação intrauterina é utilizada no tratamento da infertilidade de causa masculina nos pacientes com alterações leves na concentração espermática, volume seminal, motilidade e morfologia seminal, assim como disfunção ejaculatória e anormalidade imunológicas. Entretanto, tem sido difícil determinar com precisão sua eficácia. Vários estudos publicados na literatura discutem se a inseminação intrauterina deve ser ou não utilizada para o tratamento do fator masculino. Estudos avaliando este procedimento têm resultado em diferentes taxas de sucesso, em parte porque a infertilidade de causa masculina é definida de uma maneira diferente entre os diversos estudos e em parte porque muitos estudos avaliam uma pequena e heterogênea população de pacientes. Esta técnica deve ser utilizada em homens com oligozoospermia moderada antes de tentar técnicas mais invasivas, porque é simples e menos onerosa ${ }^{30}$.

A inseminação intrauterina pode ser utilizada como alternativa de tratamento para o casal infértil quando todos os fatores que afetam a infertilidade masculina foram corrigidos e a gravidez não foi alcançada assim mesmo. O sêmen não processado não pode ser utilizado para a inseminação intrauterina, porque contém uma elevada concentração de prostaglandinas que promovem aparecimento de contrações uterinas dolorosas. O objetivo do preparo de sêmen é aumentar a concentração de espermatozóides móveis, remover o plasma seminal, debris, prostaglandinas e outras substâncias deletérias para a viabilidade espermática e que causem contrações uterinas, além de contaminação bacteriana. As taxas de gravidez por casal variam de 0 a $66 \%$ e as taxas de gravidez por ciclo variam de 0 a $22 \%$, sendo que são superiores quando a estimulação ovariana controlada é utilizada. As taxas de sucesso dependem de muitas variáveis, incluindo se a ovulação foi induzida ou não, tempo de infertilidade e número de tentativas anteriores.

Teoricamente, tentativas para aumentar o número de oócitos podem aumentar a possibilidade de ocorrer $\mathrm{f}$ ertilização. Além disso, é possível que alterações sutis na ovulação possam ser corrigidos com a estimulação 
ovariana. Desta forma, protocolos de estimulação ovariana foram desenvolvidos. Uma correlação positiva foi observada entre taxas de gravidez e o número total de espermatozóides móveis inseminados; entretanto, alguns estudos não confirmam tal associação ${ }^{30}$.

É prudente informar a casais com idade superior a 35 anos, teratozoospermia grave (Tygerbergr $<5 \%$ ), oligoastenozoospermia grave (concentração espermática $<10$ milhões $/ \mathrm{mL}$, motilidade espermática $<30 \%$ ) ou presença de defeitos funcionais específicos nos espermatozóides que o procedimento que apresenta uma maior probabilidade de sucesso é a FIV com transferência de embriões com ou sem micromanipulação (ICSI) ${ }^{15}$. A decisão da utilização da inseminação intrauterina ou uma técnica reprodutiva artificial mais avançada deve ser individualizada em cada casal e depende da causa da infertilidade, idade, situação financeira e desejos do casal. Devemos informá-los sobre todas as possíveis formas de tratamento, assim como os custos e taxas de sucesso. Um grande número de inovações tecnológicas e científicas em medicina reprodutiva, aliadas às descobertas na biologia celular, tem alterado radicalmente as opções para o tratamento de casais inférteis nos últimos anos, possibilitando a realização do sonho da paternidade e maternidade em muitos casos.

A introdução da técnica de ICSI possibilitou que muitos homens com alterações seminais gerassem seus próprios filhos. É importante avaliar se o objetivo do médico envolvido com o tratamento do homem infértil é instituir um tratamento caro, porém eficaz, ou tratar o fator masculino da infertilidade fazendo com que, desta forma, o casal possa naturalmente ter quantos filhos quiser. O papel do urologista na era da ICSI é enfatizar a importância da avaliação do fator masculino. Desta forma, o urologista participa do diagnóstico e tratamento do casal infértil nos seguintes pontos: avaliação, detecção e tratamento de possíveis causas potencialmente curáveis que podem causar risco de vida (por exemplo, câncer); causas reversíveis de infertilidade masculina são inúmeras, e estas devem tratadas; as técnicas de reprodução assistida não são sempre custo-efetivas comparado a outras modalidades de tratamento convencional.

Finalmente, o papel do urologista no tratamento dos casos de fator masculino permanece como de fundamental importância, partindo do ponto de vista que novas técnicas de captação espermática ficaram estabelecidas. Apesar de alguns centros de reprodução assistida relatarem taxas de gravidez superiores a $30 \%$ com a utilização da ICSI, essa técnica é inferior na relação custo-benefício comparado às opções de tratamento utilizadas para infertilidade masculina como: correção da varicocele, desobstrução dos ductos ejaculadores, reversão de vasectomia e correção de outras azoospermias obstrutivas.

Em conclusão, a ICSI foi um marco importante no tratamento do homem infértil, mas sua eficácia e efeitos tardios ainda necessitam investigação intensiva. Apenas o emprego de uma relação harmoniosa entre o urologista e o ginecologista pode resultar em um tratamento eficaz do casal infértil sem riscos maiores.

\section{Tratamentos que alteram o tipo ou descartam a utilização da técnica de reprodução assistida utilizada}

As terapias efetivas para o tratamento da infertilidade devem idealmente fazer com que os casais inférteis se tornem capazes de estabelecer gravidez por meio do intercurso sexual. Entretanto, várias técnicas de reprodução assistida são geralmente utilizadas no manejo dos casais inférteis. O tratamento da fertilidade, seja médico ou cirúrgico, que permite o uso efetivo de opções terapêuticas menos invasivas e de menor custo é considerado benéfico. A existência de alguma forma de tratamento que reduza a necessidade da utilização de técnicas de reprodução assistida deve ser discutida com o paciente quando as opções de tratamento são abordadas. Esta abordagem não apenas promove o melhor entendimento dos casais sobre o processo de tratamento envolvido, mas igualmente permite que tenham uma expectativa realista sobre os resultados do tratamento.

Modificações no estilo de vida é uma medida importante que pode potencialmente melhorar o prognóstico dos tratamentos para os pacientes inférteis ${ }^{21}$ inseminação intrauterina Os pacientes devem evitar saunas, calções apertados, uso de cigarros e qualquer outro fator que pode afetar a espermatogênese. Além disso, evitar medicamentos como substâncias hormonais (esteróides anabolizantes, glicocorticóides, anti-androgênios), cardiovasculares (espironolactoma, bloqueadores dos canais de cálcio), neurológicos (antagonistas dopaminérgicos, fenotiazina), antimicrobianos (nitrofurantoína, sulfasalazina, dapsona), quimioterápicos e recreacionais (opióides, maconha, nicotina, álcool).

Mesmo que muitos pacientes com espermatozóides no ejaculado após a varicocelectomia não consigam estabelecer gravidez, a melhora da qualidade seminal permite que tais pacientes, até então azoospérmicos, estabeleçam gravidez com a inseminação intrauterina ou, na melhor das hipóteses, FIV com transferência de embriões ou ICSI com uso de espermatozóides no ejacu- 
lado, sem a necessidade de um procedimento adicional de captação de espermatozóides do testículo ${ }^{27}$ inseminação intrauterina. Mesmo nos pacientes que não apresentam melhora na qualidade seminal após a varicocelectomia, tal procedimento cirúrgico pode promover uma possível melhora na qualidade testicular, aumentando, desta forma, a possibilidade de captação de espermatozóides do testículo ${ }^{31}$ inseminação intrauterina.

Quando se avalia a melhor forma de tratamento para os pacientes com azoospermia obstrutiva, a literatura é clara ao demonstrar que os procedimentos microcirúrgicos são superiores na relação custo-benefício ao comparar com as técnicas de reprodução assistida. Entretanto, a disparidade entre as taxas de permeabilidade da anastomose microcirúrgica e as taxas de gravidez resulta em alguns questionamentos ${ }^{19,20}$ inseminação intrauterina. Muito embora as técnicas de reprodução assistida sejam necessárias nestes casos, a reconstrução microcirúrgica não deve ser considerada como um procedimento desnecessário. Em primeiro lugar, com a conversão do estado de azoospermia para oligozoospermia, o paciente que possui espermatozóides no ejaculado poderá utilizar as técnicas de reprodução assistida sem a necessidade de um procedimento cirúrgico adicional. Desta forma, a reconstrução microcirúrgica com sucesso (permeabilidade da anastomose do trato reprodutivo) melhora o estado de fertilidade do paciente (azoospermia), tornando-o candidato à ICSI com espermatozóides do ejaculado, inseminação intrauterina e até mesmo torna o paciente capaz de estabelecer gravidez naturalmente.

\section{Referências}

1. World Health Organization. WHO laboratory manual for the examination of human semen and sperm-cervical mucus interaction. Cambridge: Cambridge University Press; 1999.

2. Galarneau CJ, Nagler HM. Cost-effective infertility therapies in the '90s: to treat or to cure? Contemp Urol. 1999; 11 (1):32-45.

3. Carlsen E, Giwercman A, Keiding N, Skakkebaek NE. Evidence for decreasing quality of semen during past 50 years. BM. 1992; 305(6854):609-13

4. Pasqualotto FF, Pasqualotto EB, Agarwal A, Thomas AJ Jr. Detection of testicular cancer in men presenting with infertility. Rev Hosp Clin Fac Med Sao Paulo. 2003; 58(2):75-80.

5. Pasqualotto FF, Sobreiro BP, Hallak J, Athayde KS, Pasqualotto EB, Lucon AM. High percentage of abnormal semen parameters in a prevasectomy population. Fertil Steril. 2006; 85(4):954-60.

6. Pasqualotto FF, Sharma RK, Nelson DR, Thomas AJ Jr, Agarwal A. Relationship between oxidative stress, semen characteristics, and clinical diagnosis in men undergoing infertility investigation. Fertil Steril. 2000; 73(3):459-64.

7. Turek PJ. Practical approaches to the diagnosis and management of male infertility. Nat Clin Pract Urol. 2005; 2(5):226-38.

8. Shefi $S$, Turek PJ. Definition and current evaluation of subfertile men. Int Braz J Urol. 2006; 32(4):385-97.

9. Pasqualotto EB, Pasqualotto FF. Espermograma e testes de função espermática. Femina. 2006; 34(2):91-8

10. Misell LM, Holochwost D, Boban D, Santi N, Shefi S, Hellerstein $M K$, et al. A stable isotope-mass spectrometric method for measuring human spermatogenesis kinetics in vivo. J Urol. 2006 175(1):242-6.

11. Guzick DS, Overstreet JW, Factor-Litvak P, Brazil CK, Nakajima ST, Coutifaris $C$, et al. Sperm morphology, motility, and concentration in fertile and infertile men. N Engl J Med. 2001; 345(19):1388-93.

12. Kruger TF, Acosta AA, Simmons KF, Swanson RJ, Matta JF, Oehninger S. Predictive value of abnormal sperm morphology in in vitro fertilization. Fertil Steril. 1988; 49(1): 1 12-7.

13. Pasqualotto FF, Pasqualotto EB. The role of biochemical markers in male reproduction. Obstet Gynaecol Today. 2004; 9(5):301-7.
14. Carrara RC, Yamasaki R, Braganca W, Raskin S, Sartorato EL, Pina-Neto JM. Etiologic investigations on male infertility before intracytoplasmatic sperm injection (ICSI). Genet Couns. 2006; 17(3):385-9

15. Tesarik J, Mendoza G. Treatment of severe male infertility by micromanipulation-assisted fertilization: an update. Front Biosci. 2007; 12(1):105-14.

16. Pasqualotto FF, Lucon AM, de Goes PM, Sobreiro BP, Hallak J, Pasqualotto $E B$, et al. Is it worthwhile to operate subclinical righ varicocele in patients with grade II-III varicocele in the left testicle? J Assist Reprod Genet. 2005; 22(5):227-31 .

17. Li Z, Wang L, Cai J, Huang H. Correlation of sperm DNA damage with IVF and ICSI outcomes: a systematic review and meta-analysis. J Assist Reprod Genet. 2006; 23(9-10):367-76.

18. Pasqualotto FF, Rossi LM, Guilherme P, Ortiz V, laconelli A Jr, Borges $E$ Jr. Etiology- specific outcomes of intracytoplasmic sperm injection in azoospermic patients. Fertil Steril. 2005; 83(3):606-1 1 .

19. Meng MV, Greene KL, Turek PJ. Surgery or assisted reproduction? A decision analysis of treatment costs in male infertility. J Urol. 2005; 174(5): 1926-31.

20. Pasqualotto FF, Lucon AM, Sobreiro BP, Pasqualotto EB, Arap $S$. The best infertility treatment for vasectomized men: assisted reproduction or vasectomy reversal? Rev Hosp Clin Fac Med Sao Paulo. 2004; 59(5):312-5.

21. Pasqualotto FF, Lucon AM, Sobreiro BP, Pasqualotto EB, Arap $S$. Effects of medical therapy, alcohol, smoking, and endocrine disruptors on male infertility. Rev Hosp Clin Fac Med Sao Paulo. 2004; 59(6):375-82

22. Potts JM, Pasqualotto FF. Seminal oxidative stress in patients with chronic prostatitis. Andrologia. 2003; 35(5):304-8.

23. Pasqualotto FF, Lucon AM, de Goes PM, Sobreiro BP, Hallak J, Pasqualotto EB, et al. Semen profile, testicular volume, and hormonal levels in infertile patients with varicoceles compared with fertile men with and without varicoceles. Fertil Steril. 2005 83(1):74-7.

24. Pasqualotto FF, Pasqualotto EB. Tratamento do homem infértil com varicocele. JBM J Bras Med. 2006; 90(1/2):38-46. 
25. Daitch JA, Bedaiwy MA, Pasqualotto EB, Hendin BN, Hallak J, Falcone $\mathrm{T}$, et al. Varicocelectomy improves intrauterine insemination success rates in men with varicocele. J Urol. 2001; 165(5):1510-3.

26. Schlegel PN. Is assisted reproduction the optimal treatment for varicocele-associated male infertility? A cost-effectiveness analysis. Urology. 1997; 49(1):83-90.

27. Jarow JP, Sharlip ID, Belker AM, Lipshultz LI, Sigman M, Thomas A Jr, et al. Best practice policies for male infertility. J Urol. 2002; 167(5):2138-44.

28. Evers JL, Collins JA. Assessment of efficacy of varicocele repair for male subfertility: a systematic review. Lancet. 2003; 361 (9372):1849-52.
29. Potts JM, Pasqualotto FF, Nelson D, Thomas AJ Jr, Agarwal A. Patient characteristics associated with vasectomy reversal. J Urol. 1999; $161(6)$ : 1835-9.

30. Pasqualotto EB, Agarwal A. Effect of male factor on pregnancy outcome in patients undergoing intrauterine insemination. In: Allahbadia G, editor. Intrauterine insemination. Mumbai: Rotunda 1998. p. 117-27.

31. Pasqualotto FF, Sobreiro BP, Hallak J, Pasqualotto EB, Lucon $A M$. Induction of spermatogenesis in azoospermic men after varicocelectomy repair: an update. Fertil Steril. 2006; $85(3): 635-9$. 